\title{
A Delocalized Cobaltoviologen with Seven Reversibly Accessible Redox States and Highly Tunable Electrochromic Behaviour
}

\author{
Iram F. Mansoor, ${ }^{\text {a }}$ Derek I. Wozniak, ${ }^{a}$ Yilei Wu, ${ }^{\text {b }}$ and Mark C. Lipke
}

Co" mediates electronic coupling between two $\mathrm{N}$-Me-pyridiniumterpyridine ligands that are related to redox-active $\mathrm{N}, \mathrm{N}$-dialkyl-4,4'bipyridinium dications (viologens). Borderline Class II/III electronic delocalization imparts the cobaltoviologen complex with distinct electronic properties (e.g. 7 accessible redox states) relative to those of viologens, leading to enhanced electrochromic properties.

There is strong interest in tuning the reduction potentials, electron-transfer rates, reactivities, and other chemical or physical properties of redox-active species to provide optimized components for a variety of applications (e.g. electrochromic materials, ${ }^{1}$ flexible electronics, ${ }^{1}$ photovoltaics, ${ }^{2}$ and electrocatalysis $\left.{ }^{3}\right)$. Viologens $(N, N-$ dialkyl-4,4'-bipyridinium dications, Scheme $1 \mathrm{~A})^{4}$ are an important class of redox-active organic molecules that have been applied in many such roles, leading to considerable research effort aimed at tuning the electronic properties of these dications.5,6 Replacement of one of the alkyl groups with a metal, to produce a metalloviologen, is intriguing in this regard, especially since metal complexes with various redox-active ligands often exhibit properties exceeding the sum of their parts. ${ }^{3}$ However, metalloviologens are consistently

Scheme 1. Redox states of viologens and cobaltoviologen $\mathbf{1}^{4+}$.

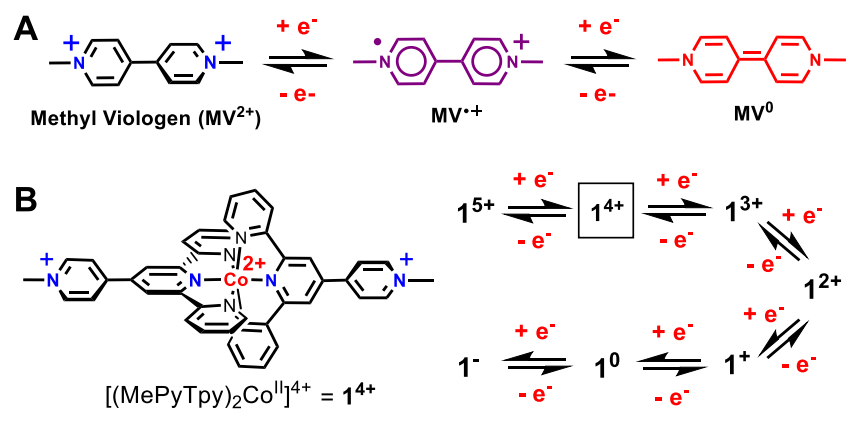

\footnotetext{
a. Department of Chemistry and Chemical Biology, Rutgers, The State University of New Jersey, 123 Bevier Road, Piscataway, New Jersey 08854-, United States b. Department of Chemical Engineering, Stanford University, Stanford, California 94305-4125, United States

Electronic Supplementary Information (ESI) available. CVs, UV-vis-NIR and ${ }^{1} \mathrm{H}$ NMR spectra, structural data. Details of syntheses, Evans method measurements, singlecrystal XRD analyses.
}

dominated by simple viologen-like redox characteristics, limiting any added value vs. typical organic viologens. ${ }^{7-9}$

More notable electronic properties might be obtained by enhancing metal-ligand or ligand-ligand electronic coupling in metalloviologens since delocalization is a key feature in many important complexes with redox-active ligands (e.g. dithiolene complexes). ${ }^{10}$ Derivatives of $\left[(\mathrm{tpy}){ }_{2} \mathrm{Co}\right]^{2+}$ are logical targets for realizing electronic delocalization in metalloviologens, as the $\mathrm{Co}^{11 / /}$ redox couple (ca. $-1.13 \mathrm{~V}$ vs. $\mathrm{Fc}^{+/ 0}$ in $\mathrm{MeCN}$ ) lies between the two reductions of dialkyl viologens (ca. $-0.82 \mathrm{~V},-1.24 \mathrm{~V}$ ), suggesting a good metal-ligand energy match. ${ }^{4,11}$ We thus examined the redox properties of the known complex $\left[(\mathrm{MePyTpy})_{2} \mathrm{Co}{ }^{11}\right]^{4+}\left(\mathbf{1}^{4+}\right.$, Scheme $\left.1 \mathrm{~B}\right)$, revealing that this complex indeed displays unusual electronic features that have previously been overlooked, including five accessible reduced states (and seven redox states total) rather than just the two reduced states typical of viologens and other metalloviologens. As a result, the electrochromic behaviour of $\mathbf{1}^{\text {n+ }}$ is highly tunable via the applied redox potential, demonstrating an advantage in one of the prominent applications of organic viologens. This behavior was confirmed to arise from $\pi$-electron delocalization in the reduced states of $\mathbf{1}^{\mathbf{n +}}$, as evident from structural and spectroscopic data showing that cobalt mediates Class III or borderline Class II/III electronic coupling between the ligands in the $\mathbf{1}^{\mathbf{3 +}}$ state.

Unlike many other metalloviologens, the redox properties of $\left[(\mathrm{RPyTpy})_{2} \mathrm{Co} "\right]^{4+}$ complexes have not previously been characterized in detail. Aqueous electrochemical studies of a $\left[(\text { RPyTpy })_{2} \mathrm{Co}^{11}\right]^{4+}{ }_{n}$ coordination polymer have been reported but were very limited (vide infra). ${ }^{12}$ Therefore, we began our investigations by examining $\mathbf{1}^{4+} \cdot 4 \mathrm{PF}_{6}$ by cyclic voltammetry in anhydrous MeCN (Figure $1 \mathrm{~A}, \mathrm{~B})$. The Co ${ }^{111 / 1}$ redox couple $\left(E_{1 / 2}=\right.$ $-0.03 \mathrm{~V}$ vs. $\left.\mathrm{Fc}^{+/ 0}\right)$ is similar to that of $\left[(\mathrm{tpy}){ }_{2} \mathrm{Co}^{\prime \prime}\right]^{2+}\left(E_{1 / 2}=-0.09\right.$ $\mathrm{V}){ }^{11}$ indicating that the cationic pyridinium groups exert minimal inductive influence on the cobalt centre in $\mathbf{1}^{\mathbf{4 +}}$. However, $\mathbf{1}^{\mathbf{4 +}}$ exhibits five reversible $1 \mathrm{e}^{-}$reductions, whereas typical $\left[\left(\text { tpy) }{ }_{2} \mathrm{Co}^{\prime \prime}\right]^{2+}\right.$ complexes show only two (a Coll// reduction and a terpy-centred reduction). ${ }^{11,13}$ The redox behaviour of $\mathbf{1}^{4+}$ is also more intricate than that reported for its iron counterpart 

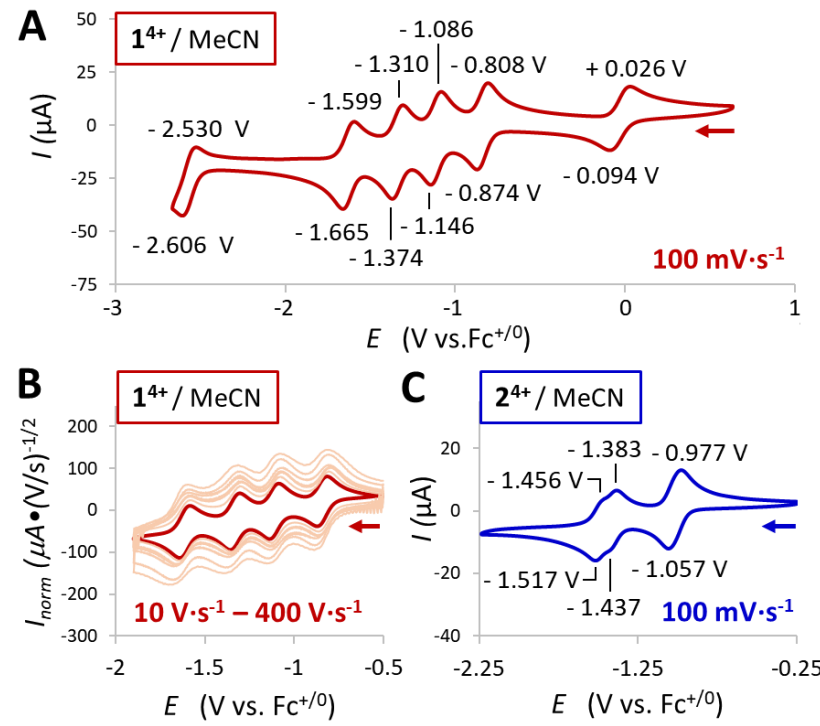

Figure 1. Cyclic voltammograms recorded in $\mathrm{MeCN}$ with $0.1 \mathrm{M}\left[\mathrm{Bu}_{4} \mathrm{~N}\right]\left[\mathrm{PF}_{6}\right]$ supporting

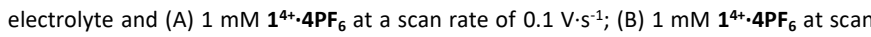
rates of $10-400 \mathrm{~V} \cdot \mathrm{s}^{-1}$; and (C) $1 \mathrm{mM} \mathbf{2} \cdot 4 \mathrm{PF}_{6}$ at a scan rate of $0.1 \mathrm{~V} \cdot \mathrm{s}^{-1}$.

$\left[(\mathrm{MePyTpy})_{2} \mathrm{Fe}^{11}\right]^{4+}$, which exhibits just two ligand-based $2 \mathrm{e}^{-}$ redox couples. ${ }^{7}$ Thus, the redox properties of $\mathbf{1}^{4+}$ are much more complex than those of closely related compounds.

Four of the reductions of $\mathbf{1}^{4+}$ occur at moderately cathodic potentials of $E_{1 / 2}=-0.84,-1.12,-1.34$, and $-1.63 \mathrm{~V}$, a range that overlaps with, but is wider than, that of the two ligand-based $2 \mathrm{e}^{-}$redox couples of $\left[(\mathrm{MePyTpy})_{2} \mathrm{Fe}^{\prime \prime}\right]^{4+}\left(E_{1 / 2}=-1.05,-1.50 \mathrm{~V}\right)$. The redox behaviour of this iron complex is similar to that of dialkyl viologens, indicating that the two ligands behave independently of the iron centre and each other. In contrast, separation of the reductions into four distinct $1 \mathrm{e}^{-}$events in $\mathbf{1}^{4+}$ suggests significant electronic coupling between the two ligands and/or between the ligands and cobalt, consistent with a good energy match expected between cobalt and the ligands.

To confirm the role of $\mathrm{Co}$ in the redox behaviour of $\mathbf{1}^{4+}$, the redox properties of a $\mathrm{Zn}$ and $\mathrm{Ni}$ analogue ( $\mathbf{2}$ and $\mathbf{3}$, respectively) were examined. The $\mathrm{CV}$ s of both control complexes (Figure $1 \mathrm{C}$ and Figure 56$)$ are very similar, consisting of a $2 \mathrm{e}^{-}$reduction $\left(E_{1 / 2}\right.$ $=-1.02 \mathrm{~V}, 2 ;-1.03 \mathrm{~V}, 3)$ followed by two closely overlapping $1 \mathrm{e}^{-}$ reductions $\left(E_{1 / 2} \approx-1.41,-1.49 \mathrm{~V}, \mathbf{2} ;-1.46,-1.54 \mathrm{~V}, \mathbf{3}\right)$. This behaviour is similar to that reported for the Fe analogue, 7 confirming that the electronic properties of the cobalt complex $1^{4+}$ are truly unique among this series. The control complexes also shed light on the reversible 10/- redox couple, which occurs at $E_{1 / 2}=-2.57 \mathrm{~V}$. Both 2 and $\mathbf{3}$ exhibit irreversible reductions near this potential (Figures S5,6), suggesting that the $\mathbf{1}^{\text {o/- }}$ couple may be ligand based since it does not rely on the cobalt-centre.

We next sought to examine how the unusual electronic properties of $\mathbf{1}^{\mathbf{4 +}}$ influence its behaviour in roles characteristic of purely organic viologens. Viologens are important as electron acceptors and relays, ${ }^{14}$ so the electron transfer properties of $\mathbf{1}^{\text {n+ }}$ were examined by recording CVs at varying scan rates. The four closely grouped redox couples exhibit nearly ideal reversibility up to scan rates of $10 \mathrm{~V} \cdot \mathrm{s}^{-1}$, and peak separations are increased only moderately at $400 \mathrm{~V} \cdot \mathrm{s}^{-1}$ (Figure $1 \mathrm{~B}$ ). These data were used to calculate heterogeneous electron transfer rate constants of $k_{e} \approx 0.5,0.7,0.7$, and $0.3 \mathrm{~cm} \cdot \mathrm{s}^{-1}$ for these four successive reductions. ${ }^{15}$ These rates are higher than reported for organic viologens $^{16}$ and about one-fourth to one-half of commonly reported values for ferrocene. ${ }^{17}$ Thus, $1^{n+}$ appears to possess excellent $\mathrm{e}^{-}$transfer capabilities across multiple redox states.

Electrochromism is another notable property of viologens, ${ }^{1}$ so UV-vis-NIR spectra of $\mathbf{1}^{4+}$ to $\mathbf{1}^{+}$were measured to quantify how delocalization influences the colouration of the viologenlike ligands. Spectra were recorded in $\mathrm{MeCN}$ after reduction of $\mathbf{1}^{4+}$ via electrolysis (Figure $2 \mathrm{~A}$ ), revealing drastically different spectral features than those of organic viologen radicals. The red colour of $\mathbf{1}^{\mathbf{4 +}}$ gives way to blue-green in $\mathbf{1}^{\mathbf{3 +}}$, which arises from increased absorptivity at $\lambda>550 \mathrm{~nm}$. Notably, a broad NIR band $\left(\lambda_{\max }=1455 \mathrm{~nm}\right)$ is observed, consistent with intervalence charge transfer (IVCT) arising from electronic coupling of mixedvalent redox centres (see below). ${ }^{18}$ Reduction to $\mathbf{1}^{\mathbf{2 +}}$ and then $\mathbf{1}^{+}$ results in the growth of an intense feature near $640 \mathrm{~nm}$, giving $\mathbf{1}^{2+}$ a deep green colour and $\mathbf{1}^{+}$an even darker blue colour. $\mathbf{1}^{\mathbf{2 +}}$ and $1^{+}$also exhibit broad charge transfer bands ( $\lambda_{\max }=880$, $1110 \mathrm{~nm}, \mathbf{1}^{2+} ; 862 \mathrm{~nm}, \mathbf{1}^{+}$). It is notable that the absorptivity of $\mathbf{1}^{\mathbf{n +}}$ increases in the visible region upon each reduction since this could be used to tune the darkness of $\mathbf{1}^{\text {n+ }}$ in electrochromic applications, whereas viologens have only one coloured state. Darkening continues into the $\mathbf{1}^{\mathbf{0}}$ state (Figure $2 \mathrm{~A}$, inset), and the spectrum of isolated $\mathbf{1}^{0}$ in toluene is presented in Figure S18.

The electrochromic behaviour of $\mathbf{1}^{\mathrm{n}+}$ expands considerably upon that of a [(RPyTpy $\left.)_{2} \mathrm{Co}^{\prime 1}\right]^{4+}{ }_{n}$ polymer, for which only one reduced spectrum was recorded (to a limit of $\lambda \leq 800 \mathrm{~nm}$ ) in water at a potential that should access the doubly reduced state $(2+)$ of the cobaltoviologens. ${ }^{12}$ However, the reported spectrum matches $\mathbf{1}^{\mathbf{3 +}}$ rather than $\mathbf{1}^{\mathbf{2 +}}$ (see Figure S20), suggesting the polymer was not efficiently reduced. We recorded aqueous CVs of $\mathbf{1}^{4+}$ at $\mathrm{pH} 7.2$ (Figures $\mathrm{S} 4$ ) indicating $\mathbf{1}^{\text {n+ }}$ has limited stability in water at potentials negative of its $\mathbf{1}^{2+}$ state, possibly due to $\mathrm{H}^{+}$ reduction activity. This limited aqueous stability may contribute to the discrepancy between our UV-vis data in MeCN and that reported for the cobaltoviologen polymer in water.

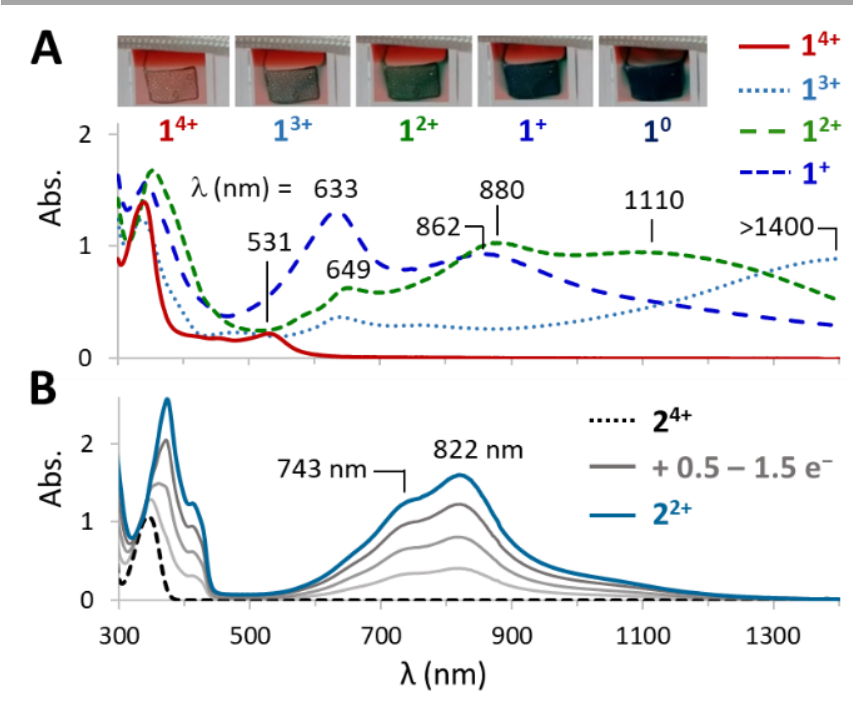

Figure 2. UV-vis-NIR spectra ( $M e C N, 1 \mathrm{~mm}$ path) of (A) $\mathbf{1}^{4+}$ to $\mathbf{1}^{+}$accessed by electrolysis of a $0.5 \mathrm{mM}$ solution of $\mathbf{1}^{4+} \cdot \mathrm{PF}_{6}$. Inset shows $\mathbf{1}^{4+}$ to $\mathbf{1}^{\mathbf{0}}$ at a Pt mesh electrode. (B) $\mathbf{2}^{4+}$ to $\mathbf{2}^{2+}$ accessed by $4 \times 0.5$ equiv additions of $\mathrm{Cp}_{2} \mathrm{Co}$ to a $1 \mathrm{mM}$ solution of $\mathbf{2 \cdot 4} \mathbf{P F}_{6}$ 
The distinct spectra of $\mathbf{1}^{+}-\mathbf{1}^{\mathbf{3}+}$ likely arise from electronic delocalization in these states, as indicated by their broad NIR bands. The spectrum of $\mathbf{2}^{\mathbf{2 +}}$ lacks such bands, instead showing an intense absorption at $\lambda_{\max }=822 \mathrm{~nm}$ with a shoulder at 743 $\mathrm{nm}$ (Figure 2B). These features are reminiscent of the spectra of viologen radical cations in terms of molar absorptivity $\left(\varepsilon_{\max }=\right.$ $16,050 \mathrm{M}^{-1} \mathrm{~cm}^{-1}$ per ligand in $\left.\mathbf{2}^{2+} ; 13,900 \mathrm{M}^{-1} \mathrm{~cm}^{-1}, \mathbf{M V}^{+\bullet}\right)$ and shape, but viologen radicals absorb at shorter wavelengths $\left(\lambda_{\max }\right.$ $\left.=607 \mathrm{~nm}, \mathbf{M V}^{+\bullet}\right) \cdot{ }^{19}$ The spectrum of $\mathbf{2}^{2+}$ grows in equal steps upon $4 \times 0.5$ equiv additions of $\mathrm{Cp}_{2} \mathrm{Co}\left(E^{\circ}=-1.3 \mathrm{~V}\right)$ to $2^{4+}$, as expected in the absence of ligand-ligand electronic coupling. A nearly identical spectrum was observed for $\mathbf{3}^{2+}$ (Figure S25), confirming that $\mathbf{1}^{\text {n+ }}$ is distinct in its electronic properties.

A spectrum of $\mathbf{1}^{3+}$ extending to $4,000 \mathrm{~cm}^{-1}(2,500 \mathrm{~nm})$ was acquired using a complementary FTIR instrument, allowing ligand-ligand coupling to be quantified by analysis of the full IVCT band (Figure 3 ). The experimental bandwidth at half height $\left(v_{1 / 2}=2481 \mathrm{~cm}^{-1}\right)$ is significantly narrower than the theoretical value calculated on the basis of the Marcus-Hush two state model ${ }^{20}\left(v^{\circ}{ }_{1 / 2}=3989 \mathrm{~cm}^{-1}\right)$, providing an electronic coupling parameter $\left(H_{\mathrm{ab}}=922 \mathrm{~cm}^{-1}\right)$ that indicates borderline Class II/III delocalization ${ }^{21,22}$ in $\mathbf{1}^{3+}$, consistent with the large $275 \mathrm{mV}$ separation between the first and second reductions of $\mathbf{1}^{4+} .18$ Similar separations are observed for the second, third, and fourth reductions ( $226 \mathrm{mV}$ and $253 \mathrm{mV}$, respectively, Figure 1), but spectral analysis of delocalization in $\mathbf{1}^{\mathbf{2 +}}$ and $\mathbf{1}^{+}$is currently not meaningful because it is unclear if these states feature Co" or $\mathrm{Co}^{\prime}$ (Scheme 2). Thus, assignment of the spectra of $\mathbf{1}^{2+}$ and $\mathbf{1}^{+}$ remains ambiguous, whereas the ligand-ligand IVCT band of $\mathbf{1}^{\mathbf{3}}$ can be confidently assigned based on structural data confirming the added electron is in the ligand $\pi$ system of $\mathbf{1}^{3+}$ (vide infra).

The electronic structure of $\mathbf{1}^{\mathbf{n}+}$ was further probed by Evans method magnetic moment measurements in $\mathrm{CD}_{3} \mathrm{CN}$, accessing $\mathbf{1}^{3+}-\mathbf{1}^{+}$by in situ reduction of $\mathbf{1}^{4+}$ with $\mathrm{Cp}^{*}{ }_{2} \mathrm{Co}\left(E^{\circ}=-1.9 \mathrm{~V}\right) . \mathbf{1}^{4+}$ exhibits a moment of $3.1 \mu_{B}$, indicating a mix of low-spin (l.s.) and high-spin (h.s.) Coll similar to that of the known spincrossover behaviour of $\left[(\mathrm{tpy}){ }_{2} \mathrm{Co}^{\prime \prime}\right]^{2+}$. The $\mathbf{1}^{3+}$ state maintains about the same magnetic moment, indicating $S=1$ and suggesting antiferromagnetic coupling between the reduced ligand and h.s. Co". It is plausible that this metal-ligand coupling enables a half-filled $3 \mathrm{~d}$ orbital to act as the bridge for delocalization of the added electron across both ligands in $1^{3+}$. The next two reductions increase the magnetic moment, giving $S=3 / 2$ for $\mathbf{1}^{2+}$ and $S=2$ for $\mathbf{1}^{+}$. The added electrons must be on the ligands for their spins to couple ferromagnetically with $\mathrm{Co}$, but

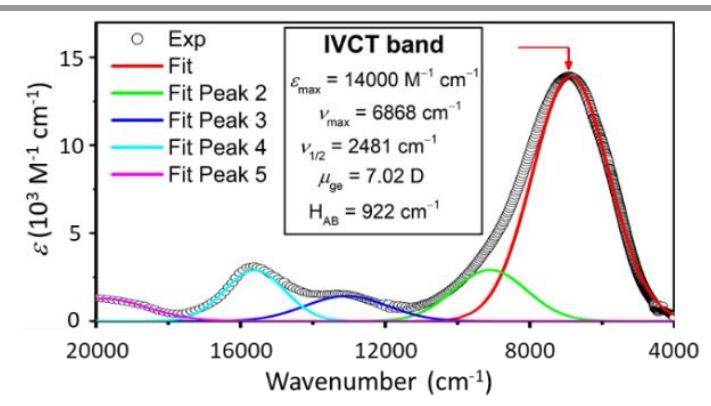

Figure 3. Fitting of the vis-NIR spectrum of $\mathbf{1}^{3+}(1 \mathrm{~mm}$ path, $0.5 \mathrm{mM}, \mathrm{MeCN})$ to gaussian curves and quantification of electronic delocalization by analysis of the IVCT band.
Scheme 2. Electronic configurations of $\mathbf{1}^{\text {n+ }}$.

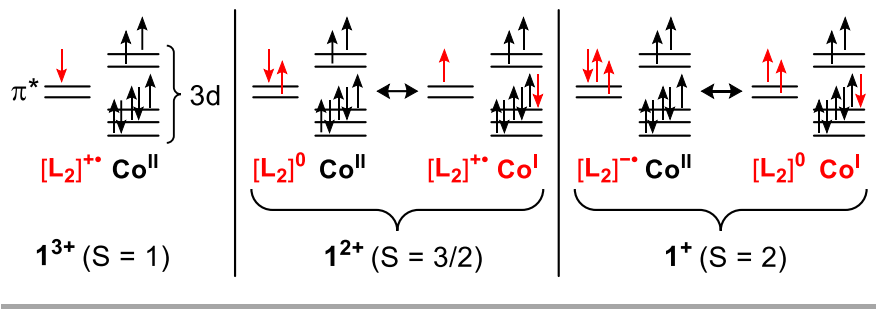

it is conceivable that the antiferromagnetically coupled electron in $\mathbf{1}^{3+}$ shifts from the ligands to cobalt upon conversion to $\mathbf{1}^{\mathbf{2 +}}$ or $\mathbf{1}^{+}$(Scheme 2). Thus, it is unclear if $\mathbf{1}^{2+}$ and $\mathbf{1}^{+}$are $\mathrm{Co}^{\prime \prime}$ or $\mathrm{Co}^{\prime}$ complexes, and they might lie between these extremes.

Notably, it was possible to observe sharp ${ }^{1} \mathrm{H}$ NMR signals for all protons in $\mathbf{1}^{\mathbf{3 +}}, \mathbf{1}^{\mathbf{2 +}}$, and $\mathbf{1}^{+}$(Figure 4 ) as long as care was taken to ensure only one state of $\mathbf{1}^{\mathrm{n}+}$ was present. Several resonances exhibited dramatic paramagnetic shifts (ca. -233 to $395 \mathrm{ppm}$ range), but it was possible to identify the $\mathrm{NCH}_{3}$ resonance of $\mathbf{1}^{3+}$ and $\mathbf{1}^{\mathbf{2 +}}$ by integration, and this signal was identified for $\mathbf{1}^{+}$by tracking its change upon substoichiometric additions of $\mathrm{Cp} *{ }_{2} \mathrm{Co}$ to $\mathbf{1}^{2+}$ (Figure $4 \mathrm{~B}$ ). Unpaired $\pi$ electrons have predictable effects on upfield vs. downfield ${ }^{1} \mathrm{H}$ NMR shifts, ${ }^{23}$ so this data enables qualitative evaluation of the presence of $\alpha$ or $\beta$ spin in the ligand $\pi$ system of $1^{3+}$ to $1^{+} . \neq$The $\mathrm{NCH}_{3}$ resonance appears upfield for $\mathbf{1}^{3+}(\delta-47 \mathrm{ppm})$, indicating considerable $\beta$ spin in the viologenlike $\pi$ system (note: the metal is assigned $\alpha$ spin), consistent with antiferromagnetic coupling between the ligand radical and Co". The next two reductions dramatically shift the $\mathrm{NCH}_{3}$ signal downfield ( $\delta 124 \mathrm{ppm}, \mathbf{1}^{\mathbf{2 +}} ; 395 \mathrm{ppm}, \mathbf{1}^{+}$), consistent with increasing $\alpha$ spin density on the ligands as expected from the magnetic moment measurements. Three other signals show large changes from $\mathbf{1}^{3+}$ to $\mathbf{1}^{+}$(Figure $3 \mathrm{~B}$ ) but with an opposite trend to the $\mathrm{NCH}_{3}$ group, indicating these arise from the $\mathrm{sp}^{2} \mathrm{CH}$ positions of the py-py ${ }^{+}$moieties. ${ }^{\ddagger}$ Signals of the flanking pyridyl groups stay in a relatively narrow range $(15-100 \mathrm{ppm})$ in all states of $\mathbf{1}^{\mathbf{n}+}$, except for one signal that moves to $143 \mathrm{ppm}$ in $\mathbf{1}^{+}$.
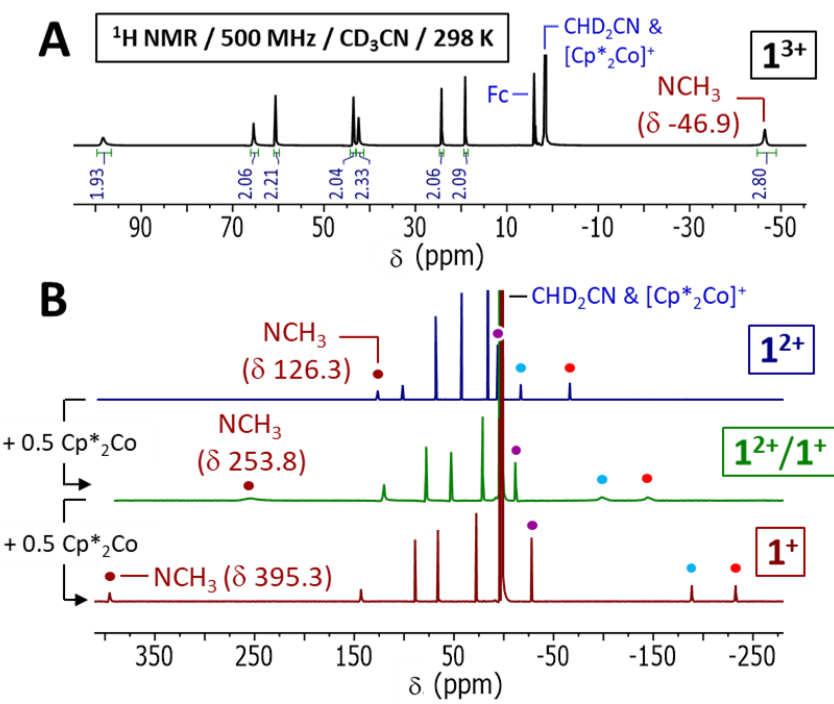

Figure 4. ${ }^{1} \mathrm{H}$ NMR spectra of (A) $1^{3+}$ formed in situ by addition of $\mathrm{Cp}^{*}{ }_{2} \mathrm{Co}$ to $1^{4+} \cdot 4 \mathrm{PF}_{6}$; (B) $\mathbf{1}^{2+}$, a $1: 1$ mixture of $\mathbf{1}^{2+}: \mathbf{1}^{+}$, and $\mathbf{1}^{+}$formed in situ by sequential additions of $\mathrm{Cp}_{2}{ }_{2} \mathrm{Co}$ to $\mathbf{1}^{4+} \cdot \mathbf{4} \mathrm{PF}_{6}$. Circles mark signals arising from the viologen-like portion of the ligands. 


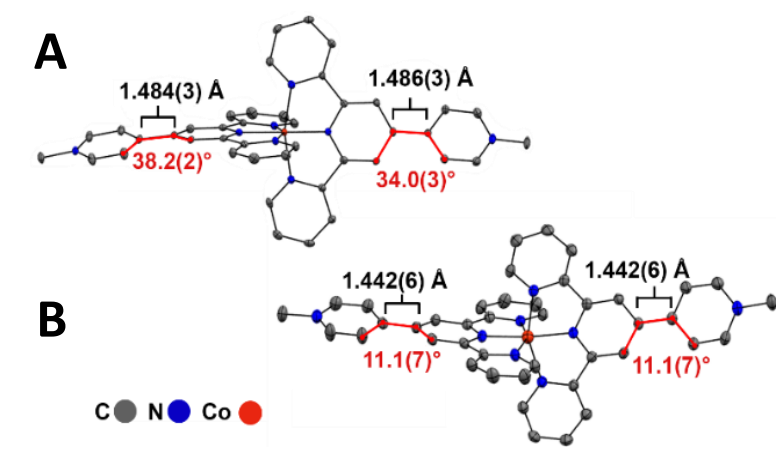

Figure 5. Single-crystal XRD structures of $(A)$ one of two independent units of $\mathbf{1}^{4+}$ in a crystal of $\mathbf{1}^{4+} \cdot \mathbf{4} \mathrm{PF}_{6}$. (B) $\mathbf{1}^{3+}$ in a crystal of $\mathbf{1}^{3+} \cdot \mathbf{3} \mathrm{PF}_{6}$.

These relatively small changes suggest that the flanking pyridyl groups are not reduced significantly in $\mathbf{1}^{3+}$ to $\mathbf{1}^{+}$, contrasting with the redox behaviour of traditional terpyridine ligands. ${ }^{13}$

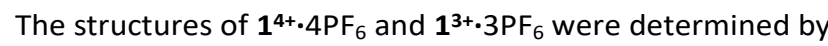
single-crystal XRD (Figure 5), revealing symmetric shortening of the pyridine-pyridinium $\mathrm{C}-\mathrm{C}$ bonds in $\mathbf{1}^{\mathbf{3 +}}(\mathrm{d}=1.442(6) \AA$ $\left.\mathrm{d}_{\text {Avg }}=1.486(4) \AA, \mathbf{1}^{4+}\right)$. Similar changes are observed for viologens upon reduction, ${ }^{4}$ indicating the ligands as the site of reduction in $\mathbf{1}^{3+}$. However, viologen radical cations typically exhibit shorter central $C-C$ bonds $\left(d_{\text {avg }}=1.426 \AA\right.$ ),$\$$ a difference that likely results from sharing of $1 \mathrm{e}^{-}$across both ligands in $\mathbf{1}^{\mathbf{3}}$ (i.e. $1 / 2 \mathrm{e}^{-}$per ligand). Likewise, a small py-py+ torsion angle (ca. $11^{\circ}$ ) is maintained in $\mathbf{1}^{\mathbf{3}+}$, whereas viologen radicals are usually planar. ${ }^{\S}$ These observations, along with the symmetry between both ligands in $\mathbf{1}^{\mathbf{3}}$, suggest even greater delocalization (Class III) in the solid state than determined in solution, further confirming strong ligand-ligand electronic coupling in $\mathbf{1}^{\mathbf{3}}$.

In summary, cobaltoviologen $\mathbf{1}^{\mathbf{4 +}}$ exhibits significantly more intricate redox behaviour than organic viologens and other metalloviologens, enhancing the electrochromic properties $\mathbf{1}^{\mathbf{4}^{+}}$ while maintaining the excellent $\mathrm{e}^{-}$transfer capabilities typical of viologens. The distinct properties of $\mathbf{1}^{\mathbf{4 +}}$ appear to arise from significant electronic delocalization in its reduced states, with spectroscopic and structural analyses confirming $\mathbf{1}^{3+}$ features strong ligand-ligand electronic coupling mediated by Co"l. Metal-mediated coupling between organic redox centres is uncommon, ${ }^{24}$ and it is remarkable that this property has long been overlooked for simple homoleptic cobaltoviologens like $\mathbf{1}^{\mathbf{4}}$, especially since other efforts to achieve strong electronic coupling between viologens have employed elaborate schemes involving macrocycles and mechanical bonds. ${ }^{25}$ In contrast, $\mathbf{1}^{4+}$ is easily prepared and similar complexes are commonly employed in (nano)materials, ${ }^{26}$ suggesting that our results are promising for the development of new functional electronic materials. We are currently exploring such possibilities, while also investigating the electronic structures of $\mathbf{1}^{\mathbf{2 +}}$ and $\mathbf{1}^{+}$.

This work was supported by Rutgers, The State University of New Jersey. We acknowledge Dr. Andrew Cook and Prof. Kate Waldie for assistance with NIR data collection.

\section{Conflicts of interest}

There are no conflicts to declare.

\section{Notes and references}

¥ Opposite signs of paramagnetic NMR shifts for the $\mathrm{NCH}_{3}$ signal vs. $\mathrm{sp}^{2} \mathrm{CH}$ signals of the py-py+ moieties indicate these shifts arise mainly from Fermi contact with unpaired $\pi$ electrons.

$\S 85 \%$ of viologen radical cation structures with $\mathrm{R}<0.1$ in the Cambridge Structure Database (July 2020) have central $\mathrm{C}-\mathrm{C}$ bonds shorter than those of the ligands in $\mathbf{1}^{3+} \cdot 3 \mathrm{PF}_{6}$. Of the viologen radical cations, $55 \%$ have central $\mathrm{C}-\mathrm{C}-\mathrm{C}-\mathrm{C}$ torsion angles $<2^{\circ}$, only $20 \%$ exceed $5^{\circ}$, and none exceed $10^{\circ}$.

1 K. Madasamy, D. Velayutham, V. Suryanarayanan, M. Kathiresan and K. Ho, J. Mater. Chem. C, 2019, 7, 4622-4637.

2 J. W. Ondersma and T. W. Hamann, Coord. Chem. Rev., 2013, 257, 1533-1543.

3 O. R. Luca and R. H. Crabtree, Chem. Soc. Rev., 2013, 42, 1440-1459.

4 T. M. Bockman and J. K. Kochi, J. Org. Chem., 1990, 55, 41274135.

5 A. T. Buck, J. T. Paletta, S. A. Khindurangala, C. L. Beck and A. H. Winter, J. Am. Chem. Soc., 2013, 135, 10594-10597.

6 C. Reus, M. Stolar, J. Vanderkley, J. Nebauer and T. Baumgartner, J. Am. Chem. Soc., 2015, 137, 11710-11717.

7 E. C. Constable, C. E. Housecroft, M. Neuburger, D. Phillips, P. R. Raithby, E. Schofield, E. Sparr, D. A. Tocher, M. Zehnder and Y. Zimmermann, J. Chem. Soc. Dalt. Trans., 2000, 2219-2228.

8 Y. Miyake, K. Nakajima, Y. Higuchi and Y. Nishibayashi, Eur. J. Inorg. Chem., 2014, 4273-4280.

9 M. Kobayashi, S. Masaoka and K. Sakai, Dalt. Trans., 2012, 41, 4903-4911.

10 R. Eisenberg and H. B. Gray, Inorg. Chem., 2011, 50, 9741-

9751.

11 S. Aroua, T. K. Todorova, P. Hommes, L. M. Chamoreau, H. U. Reissig, V. Mougel and M. Fontecave, Inorg. Chem., 2017, 56, 5930-5940.

12 D. G. Kurth, J. P. López and W. F. Dong, Chem. Commun., 2005, 2119-2121.

13 J. England, E. Bill, T. Weyhermüller, F. Neese, M. Atanasov and K. Wieghardt, Inorg. Chem., 2015, 54, 12002-12018.

14 N. T. Vo, Y. Mekmouche, T. Tron, R. Guillot, F. Banse, Z. Halime, M. Sircoglou, W. Leibl and A. Aukauloo, Angew. Chemie Int. Ed., 2019, 58, 16023-16027.

15 H. J. Paul and J. Leddy, Anal. Chem., 1995, 67, 1661-1668. 16 H. H. Yang and R. L. McCreery, Anal. Chem., 1999, 71, 40814087.

17 A. D. Clegg, N. V. Rees, O. V. Klymenko, B. A. Coles and R. G. Compton, J. Electroanal. Chem., 2005, 580, 78-86.

18 D. M. D'alessandro and F. R. Keene, Chem. Soc. Rev., 2006, 35, 424-440.

19 T. Watanabe and K. Honda, J. Phys. Chem., 1982, 86, 26172619

20 N. S. Hush, in Progress in Inorganic Chemistry, John Wiley \& Sons, Ltd, 2007, pp. 391-444.

21 C. Creutz, M. D. Newton and N. Sutin, J. Photochem.

Photobiol. A Chem., 1994, 82, 47-59.

22 R. J. Cave and M. D. Newton, Chem. Phys. Lett., 1996, 249,

15-19.

23 K. L. Bren, in Encyclopedia of Inorganic Chemistry, Wiley, 2008.

24 A. Arnold, T. J. Sherbow, R. I. Sayler, R. D. Britt, E. J.

Thompson, M. T. Muñoz, J. C. Fettinger and L. A. Berben, J. Am. Chem. Soc., 2019, 141, 15792-15803.

25 K. Cai, H. Mao, W. G. Liu, Y. Qiu, Y. Shi, L. Zhang, D. Shen, H. Chen, Y. Jiao, H. Wu, Z. Liu, Y. Feng, C. L. Stern, M. R. Wasielewski, W. A. Goddard and J. F. Stoddart, J. Am. Chem. Soc., 2020, 142, 7190-7197.

26 K. Takada, R. Sakamoto, S. T. Yi, S. Katagiri, T. Kambe and H. Nishihara, J. Am. Chem. Soc., 2015, 137, 4681-4689. 